\title{
Lignin-Carbohydrate Complexes Based Spherical Biocarriers: Preparation, Characterization, and Biocompatibility
}

\author{
Houkuan Zhao, ${ }^{1}$ Jinling Li, ${ }^{1}$ Peng Wang, ${ }^{1,2}$ Shaoqiong Zeng, ${ }^{1}$ and Yimin Xie ${ }^{1,2}$ \\ ${ }^{1}$ Research Institute of Pulp \& Paper Engineering, Hubei University of Technology, Wuhan 430068, China \\ ${ }^{2}$ Hubei Provincial Key Laboratory of Green Materials for Light Industry, Hubei University of Technology, Wuhan 430068, China \\ Correspondence should be addressed to Yimin Xie; ppymxie@scut.edu.cn
}

Received 15 September 2017; Revised 22 October 2017; Accepted 30 October 2017; Published 13 December 2017

Academic Editor: Xiaofei Tian

Copyright (c) 2017 Houkuan Zhao et al. This is an open access article distributed under the Creative Commons Attribution License, which permits unrestricted use, distribution, and reproduction in any medium, provided the original work is properly cited.

\begin{abstract}
Spherical biocarriers were prepared with lignin-carbohydrate complexes isolated from ginkgo (Ginkgo biloba L.) xylem. The specific surface and average pore size of the biocarriers were $17.15 \mathrm{~m}^{2} \mathrm{~g}^{-1}$ and $21.59 \mathrm{~nm}$, respectively. The carriers were stable in solution at $\mathrm{pH}$ 4.0 9.5. Fourier transform infrared (FT-IR) spectrum indicated that the spherical carrier was composed of lignin and polysaccharides and had a typical lignin-carbohydrate complex (LCC) structure. The contents of galactose, lignin, and total sugar were $3.30 \%, 23.9 \%$, and $64.62 \%$, respectively, making the spherical biocarriers have good physical strength and compatible with hepatocytes. It was observed using a scanning electron microscopy (SEM) that liver cells adhered to the spherical biocarriers during culture. Cell counting indicated that the proliferation of liver cells in the experimental group was significantly higher than that of the control group. The albumin secretion (ALB) value and glucose consumption of the human hepatocytes were increased by $51.7 \%$ and $38.6 \%$, respectively, by the fourth day when cultivated on the biocarriers. The results indicate that ginkgo LCC is very biocompatible and shows promise for the use as a biomaterial in the culture of human hepatocytes.
\end{abstract}

\section{Introduction}

Lignin is one of the most abundant natural products in the land-plant kingdom and is formed through phenolic oxidative coupling processes [1]. Lignin macromolecules are formed by the dehydrogenative polymerization of three monolignols: $p$-coumaryl, coniferyl, and sinapyl alcohols [2]. Some hemicellulose in the cell walls of lignified plants is linked to lignin to form lignin-carbohydrate complexes (LCC) [3]. With the development of analysis technology, more information has been reported in the literature describing the structure and properties of LCC, especially lignincarbohydrate linkage (LC bond) [4-8]. As shown in Figure 1, (Galacto)glucomannan is the most common one in the softwood hemicelluloses, which is considered to be linked to lignin moieties by chemical bonds [9]. It is a branched heteropolysaccharide consisting of two glucose epimers, $\beta$-D-glucopyranose and $\beta$-D-mannopyranose, and galactose units which are bioactive for hepatocytes. Recently, LCC as a biological material has attracted attention. Many researchers have found that lignin-carbohydrate complexes are a good natural biodegradable material $[10,11]$. In addition, LCC contains hydrophobic rigid lignin blocks and hydrophilic flexible polysaccharide blocks, making lignin-carbohydrate complexes have good amphipathy, biocompatibility, and mechanical strength [12]. The lignin and carbohydrate blocks in the LCC copolymer not only have an ideal structure for biomaterials, but also have good compatibility with animal cells [13]. The rigid lignin blocks can form lignin-protein complexes with membrane bound proteins in animal cells, enabling cells to grow [14]. Furthermore, the flexible polysaccharide blocks containing $2-5 \%$ galactan have the ability to recognize hepatocytes due to the presence of asialoglycoprotein receptors (ASGPR) on which galactose acts as a specific adhesive ligand on the hepatocytes [15-19] (Figure 2). Galactosylated substrates are useful biomaterials in the preparation of scaffolds for hepatocyte cultivation because of their specific interaction of the galactose moiety with the cell surface ASGPR [20].

In the literature describing lignin as a biomaterial, there have been two opinions which have been argued for many years. Some researchers think that although lignin has great strength, its hydrophobicity may affect animal cell adhesion 


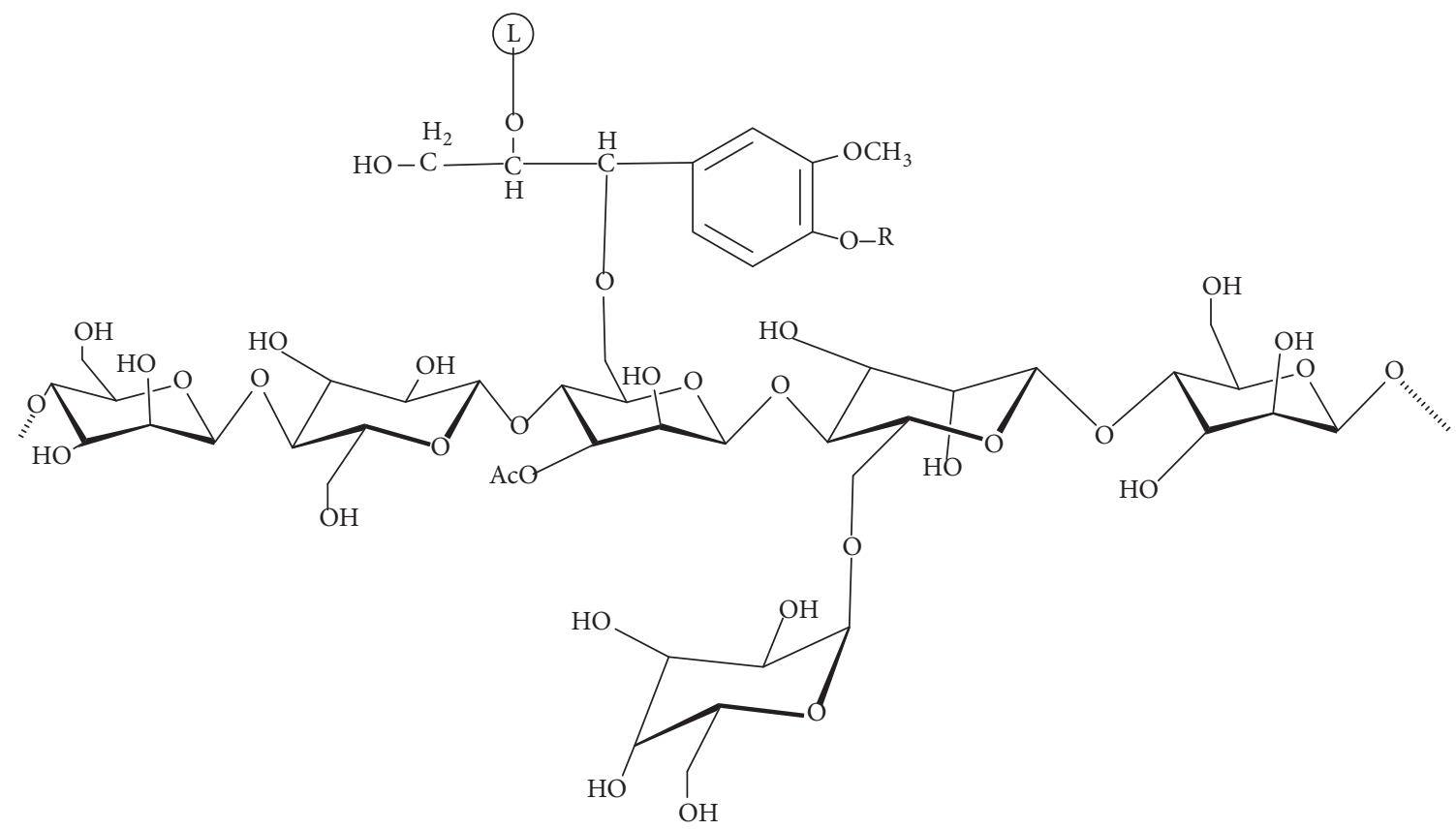

Figure 1: (Galacto)glucomannan in softwood hemicelluloses with linkage to lignin moieties ( $\mathrm{R}=\mathrm{H}$ or polylignol; $\mathrm{L}=$ polylignol).

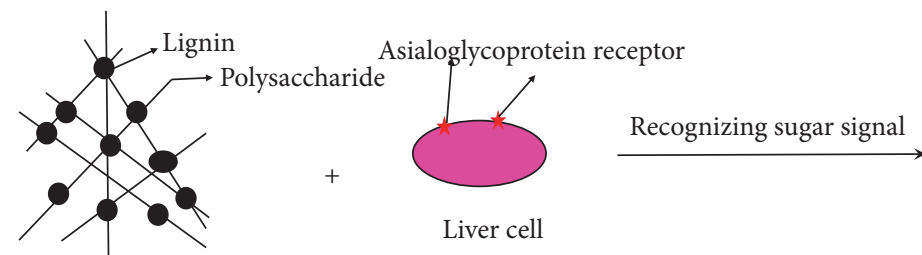

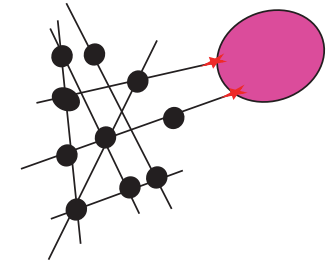

Cell adhesion on LCC

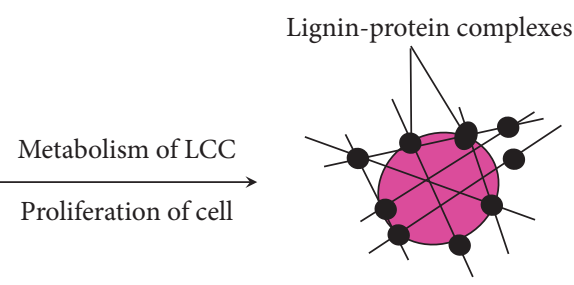

Cell stabilized on LCC

FIGURE 2: Binding of LCC material to hepatocyte.

on the lignin-based biocarriers. Other researchers suggest that lignin has many functional groups that possess physiological activity, such as methoxyl, phenolic hydroxyl, alcoholic hydroxyl, carboxyl, and carbonyl, which may promote normal metabolism of animal cells. Recently, Erakovic et al. studied the biocompatibility of modified lignin scaffold material and demonstrated that the lignin fragments in lignin-carbohydrate complexes not only have great strength, but also have good biocompatibility [21-23]. Moreover, Chung et al. [24] and Park et al. [25] demonstrated that the scaffolds immobilized by galactose retained a greater number of hepatocytes than those scaffolds which were unmodified or immobilized with galactose, due to specific interactions between hepatocytes and galactose moieties. Yang et al. [26] and Wang et al. [27] investigated the ability of hydrogels prepared with galactosylated acrylate (GAC) and poly (Nisopropylacrylamide) (NIPAAm) as scaffolds to proliferate hepatocytes and maintain the function of albumin and urea synthesis. They found that the cell adhesion and proliferation of hepatocytes occurred primarily on the surface of the hydrogels, suggesting that the incorporation of GAC containing galactose units could stimulate cell adsorption and growth, as compared with conventional PNIPAAm hydrogel. In our previous research, Wu et al. reported that hydrogel prepared from artificial LCC, that is, dehydrogenation polymer(DHP-) galactose complex, has good biocompatibility with human hepatocytes [28]. However, the biocompatibility of natural LCC with hepatocytes is still open to investigation.

In order to understand the possibility of the application of natural LCC in the tissue engineering area, LCC 
was isolated from ginkgo wood (Ginkgo biloba L.), in the group of gymnosperm. Spherical biological carriers were prepared using liquid nitrogen freeze-drying method. The spherical biocarriers with relative large specific surface area may provide more growth area for cell culture in vitro. Hepatocytes are difficult to proliferate in monolayer cultures and can be easily damaged by trypsin digestion and may be resolved using spherical biocarriers [29]. In this work, Fourier transform infrared spectroscopy (FT-IR), optical microscopy, high precision surface area, and pore size analyzer were used to characterize the structure and morphology of spherical biocarriers. The biocarriers were then used in the culture of human hepatocytes. The growth of the hepatocytes on the biocarriers was observed using an inverted biological microscope and scanning electron microscopy (SEM). The metabolic activities of the cells, including albumin secretion and glucose consumption, were also determined.

\section{Materials and Methods}

2.1. Materials. Gingko tree was obtained from Wuhan Botanical Garden. Human liver cells (L-02) were provided by Pricells Company (Wuhan, China).

2.2. Preparation of Gingko LCC. Gingko wood meal (4060 mesh) was extracted using benzene/ethyl alcohol (2/1, $\mathrm{V} / \mathrm{V}$ ) followed by a hot water treatment and then dried in vacuo for 7 days. The extractives-free wood mill was further ground for $72 \mathrm{~h}$ in a vibration ball mill with water cooling. The gingko LCC was then extracted and purified using the Björkman method [30].

2.3. Posttreatment of the LCC. The LCC were further treated with hot water at $50^{\circ} \mathrm{C}$ in order to remove the water-soluble fraction which will cause the swelling of the LCC-based spherical biocarriers. The ginkgo LCC and distilled water were put into an Erlenmeyer flask. The mixture was stirred at $50^{\circ} \mathrm{C}$ for $8 \mathrm{~h}$ and then filtered. The water-insoluble LCC fraction was obtained by freeze-drying, yield: $21.7 \%$.

2.4. Preparation of LCC-Based Spherical Biocarriers. The ginkgo LCC-based spherical biocarriers were obtained using the freeze-drying method, as shown in Figure 3. Firstly, $1 \mathrm{~g}$ water-insoluble ginkgo LCC was dissolved in $5 \mathrm{~mL}$ $90 \%(\mathrm{~V} / \mathrm{V})$ acetic acid under magnetic stirring. Secondly, the solution was dropped into liquid nitrogen using a $1 \mathrm{~mL}$ injector. Thirdly, the spherical biocarriers were obtained by drying the frozen beads using a freeze dryer (Labconco 195, USA). The morphology of spherical biocarriers was characterized using optical microscope and SEM.

2.5. FT-IR Spectroscopy. KBr pellets were prepared from $1 \mathrm{mg}$ ground sample and $60 \mathrm{mg}$ predried $\mathrm{KBr}$. The spectrum was recorded in the range of $4000 \mathrm{~cm}^{-1}-400 \mathrm{~cm}^{-1}$ using a FT-IR spectrometer (Thermo Fisher 6700, USA).

2.6. Composition of the Spherical Biocarriers Material. Threemilligram spherical biocarrier samples were hydrolyzed using
$3 \mathrm{~mL} 72 \%$ sulfuric acid at room temperature for $60 \mathrm{~min}$. The sulfuric acid was then diluted to $4 \%$ using distilled water and sample hydrolyzed for $45 \mathrm{~min}$ at $121^{\circ} \mathrm{C}$ in an autoclave. The mixture was filtered through 1G4 glass filter. The filtrate was used to detect the sugar composition of the sample using HPLC (20AT, Shimadzu) equipped with a Aminex HPX-87P column at $85^{\circ} \mathrm{C}$ using water as the eluent at speed of $0.6 \mathrm{~mL} \mathrm{~min}^{-1}$. The water-insoluble fraction was used to determine acid insoluble lignin [31].

2.6.1. SEM Observation of Spherical Biocarriers. The spherical biocarriers were put on a silicon wafer and sprayed with gold ions in vacuo. The morphological structures of surface and cross sections were observed using a JSM-6390LV SEM.

2.6.2. Diameter of the Spherical Biocarriers. The samples were examined using a stereomicroscopy (Olympus SZX16, Japan) equipped with a scale. The average diameter of the spherical biocarriers was calculated.

2.6.3. Pretreatment for Specific Surface Determination of Spherical Biocarriers. An empty tube was weighed and marked as $m_{0}$. The spherical biocarriers were put into the empty tube and treated at $120^{\circ} \mathrm{C}$ for $4.5 \mathrm{~h}$. The dried spherical biocarriers were cooled to $25^{\circ} \mathrm{C}$ in a cooling bath. The tube containing the biocarriers was weighed and marked as $m_{1}$. The value of $m_{1}$ minus $m_{0}$ was the weight of the spherical biocarriers.

2.6.4. Determination of Specific Surface. The nitrogen adsorption method $[32,33]$ was used in the determination of the specific surface using a BELSORP-mini II type high precision surface area and pore size analyzer (Ankersmid, Netherland). The Brunauer-Emmett-Teller (BET) specific surface determination is based on the gas adsorption characteristics on a solid surface. In addition, corresponding to the defined pressure, the equilibrium adsorption was definite. The equilibrium adsorption determined was equivalent to the specific surface of the sample. The formulae to calculate these are

$$
\begin{aligned}
S g & =4.36 \times \frac{V_{m}}{m}, \\
\frac{P}{V a\left(P_{0}-P\right)} & =\frac{1}{V_{m} \cdot C}+\frac{C-1}{V_{m} \cdot C} \cdot\left(\frac{P}{P_{0}}\right),
\end{aligned}
$$

where Sg is specific surface area of the sample $\left(\mathrm{m}^{2} \mathrm{~g}^{-1}\right) ; V_{m}$ is saturated nitrogen molecular monolayer adsorption $(\mathrm{mL}) ; \mathrm{Va}$ is the actual adsorption of the sample $(\mathrm{mL}) ; m$ is the weight of the sample (g); $C$ is constant related to adsorption capacity of the sample; $P$ is adsorbent partial pressure; $P_{0}$ is adsorbent saturated vapor pressure.

2.6.5. Determination of the Pore Size. The pore size was also determined using a BELSORP-mini II type high precision surface area and pore size analyzer (Ankersmid, Netherland). The gas adsorption method was used to determine the pore size. This method is based on capillary condensation and the 


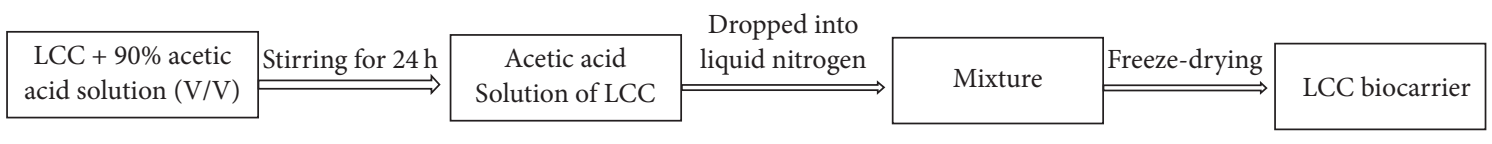

FIGURE 3: Preparation of LCC-based spherical biocarriers.

volume equivalent substitution. Corresponding to the ratio of $P / P_{0}$, there is a critical radius, $\mathrm{Rk}$. The critical radius is calculated using the Kelvin equation as follows:

$$
\mathrm{Rk}=\frac{-0.414}{\log \left(P / P_{0}\right)} .
$$

2.6.6. Size Stability of Spherical Biocarriers. Five milligrams of spherical biocarriers was suspended in $5 \mathrm{ml}$ of buffering solutions at various $\mathrm{pH}$ (acetate buffer $\mathrm{pH} 4 \sim 5$, phosphate buffer $\mathrm{pH}$ 6.8 7.4, and sodium bicarbonate buffer $\mathrm{pH} 9.5$ ). The size and morphology of spherical biocarriers in different buffering solutions were determined using a stereomicroscopy (Olympus SZX16, Japan) equipped with a scale after 15 days.

2.7. Culture of Human Hepatocytes. Human hepatocytes (L-02), obtained from Pricells Company (Wuhan, China), were rinsed with phosphate buffer. The hepatocytes were inoculated into 12-well culture plates at a density of $3 \times$ $10^{5}$ cells $\mathrm{mL}^{-1}$. The spherical biocarriers were then sterilized at $120^{\circ} \mathrm{C}$ for $4 \mathrm{~h}$. These were then added to the wells at a concentration of $2.5 \mathrm{mg} \mathrm{mL}^{-1}$. The hepatocytes together with the spherical biocarriers were incubated at $37^{\circ} \mathrm{C}, 5 \% \mathrm{CO}_{2}$, and $100 \%$ relative humidity. The culture medium used was RPMI-1640 supplemented with $20 \%$ FBS, $1 \%$ penicillin, and streptomycin solution. The adhesion of human hepatocytes to the spherical biocarriers was observed daily using a XDS1 inverted biological microscope. Cell-free supernatant was collected daily to detect the metabolic activity of the cells.

2.7.1. Cell Number Counting. On the 1 5th days of culture liquid media were collected every day. The cells were then washed twice with phosphate buffer, followed by $0.25 \%$ trypsin for $1 \sim 2 \mathrm{~min}$. The media containing trypsin were then discarded. Then the new media were added to terminate the digestion. The cells were no longer adhered to the well but in a cell suspension. Two hundred $\mathrm{mL}$ of suspension liquid was taken and mixed with equal volume of $0.4 \%$ trypan blue staining solution. Some of the stained cells were put onto a blood cell counting plate. The number of stained cells was counted using a microscope.

2.7.2. Observation of the Cells Adhesion on the Carrier by SEM. On the 3rd day of cell culture, some spherical biocarriers were removed. The spherical biocarriers were fixed using $2.5 \%$ glutaraldehyde (GA) for $12 \mathrm{~h}$ at $4{ }^{\circ} \mathrm{C}$. The spherical biocarriers were then further fixed using $0.1 \%$ osmic acid for $30 \mathrm{~min}$. After the spherical biocarriers were washed using phosphate buffer, a gradient dehydration was carried out using ethanol at concentrations of $30 \%, 50 \%, 70 \%, 80 \%, 90 \%$, and $100 \%$. The dried spherical biocarriers were put onto silicon wafer and sprayed with gold ions in vacuo. The hepatocytes adhered to the spherical biocarriers were observed using a JSM-6390LV SEM.

2.7.3. Detection of Metabolic Activity. The amount of albumin secreted was determined using the method according to the instructions of kit number A028 (provided by Nanjing Jiancheng Bioengineering Institute, China). Briefly, $10 \mu \mathrm{L}$ distilled water, standard albumin, and cell-free supernatant were added to a test tube. After the addition of $2.5 \mathrm{~mL}$ bromocresol green buffer, the samples were shaken. After the reaction was carried out for $10 \mathrm{~min}$ at room temperature, the absorption values were monitored at $628 \mathrm{~nm}$ using a UV-Vis spectrophotometer (Shimadzu 2550, Japan).

$$
\operatorname{ALB}(\mathrm{g} / \mathrm{L})=\frac{A_{1}-A_{2}}{A_{0}-A_{2}} \times C_{0},
$$

where ALB is the content $\left(\mathrm{g} \mathrm{L}^{-1}\right)$ of albumin; $A_{0}, A_{1}$, and $A_{2}$ are the absorbance values of standard tubes, sample tubes, and control groups, respectively. $C_{0}\left(\mathrm{~g} \mathrm{~L}^{-1}\right)$ is the concentration of the standard.

The amount of glucose consumed by the hepatocytes was determined using the method according to the instruction of kit number CAT361500 (provided by Nanjing Jiancheng Bioengineering Institute, China). In test tubes, $10 \mu \mathrm{L}$ distilled water, standard glucose, and cell-free supernatant were added. After the addition of $1 \mathrm{~mL}$ of a solution containing phosphate buffer ( $\mathrm{pH} 7.0$ ), phenol $10.6 \mathrm{mmol} \mathrm{L}^{-1}$, and aminoantipyrine of $70 \mathrm{mmol} \mathrm{L}^{-1}$, the samples were shaken. After the reaction was carried out for $15 \mathrm{~min}$ at $37^{\circ} \mathrm{C}$, the absorption values were determined at $505 \mathrm{~nm}$ using a UV-VIS spectrophotometer.

$$
C(\mathrm{mmol} / \mathrm{L})=\frac{A_{1}}{A_{0}} \times C_{0},
$$

where $C$ is the content $\left(\mathrm{mmol} \mathrm{L}^{-1}\right)$ of glucose. $A_{0}$ and $A_{1}$ are the absorbance values of standard tubes and sample tubes, respectively. $C_{0}\left(\mathrm{~g} \mathrm{~L}^{-1}\right)$ is the concentration of the standard.

\section{Results and Discussion}

3.1. FT-IR Analysis. A peak of $3419.2 \mathrm{~cm}^{-1}$ was assigned to the hydroxyl groups of gingko LCC, as shown in Figure 4. The strong absorption of C-O stretch at $1035.6 \mathrm{~cm}^{-1}$ indicated the presence of polysaccharides [34]. The peaks at $1510 \mathrm{~cm}^{-1}$ and $1423.2 \mathrm{~cm}^{-1}$ were related to the vibration of aromatic structures in the lignin moieties [35]. FT-IR analysis confirmed that the spherical biocarriers had a typical LCC structure composed of lignin and polysaccharides. Rigid hydrophobic lignin and flexible hydrophilic polysaccharide fragments gave 
TABLE 1: Composition of ginkgo LCC-based biocarrier.

\begin{tabular}{lccccccc}
\hline Composition & Lignin & Glucose & Xylose & Galactose & Arabinose & Mannose & Total sugars \\
\hline Content $\%$ & 25.5 & 22.30 & 10.93 & 3.30 & 6.15 & 21.94 & 64.62 \\
\hline
\end{tabular}

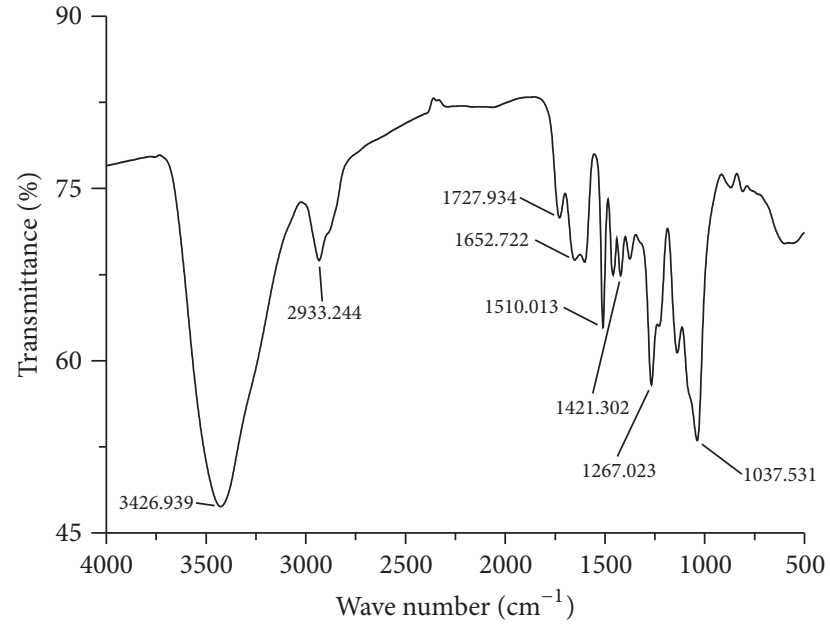

FIGURE 4: FT-IR spectroscopy of the LCC-based spherical biocarriers.

the spherical biocarriers good amphipathy properties and high strength, which are essential requirements of natural medical materials.

3.2. Composition Analysis. Galactose can be recognized by a receptor on hepatocytes and has a high physiological activity for hepatocytes [36]. Galactose was used to enhance the selective interactions between biocarriers and hepatocytes. As shown in Table 1, the content of galactose units in the LCC macromolecule was 3.30\%. The contents of lignin and total sugars were $25.5 \%$ and $64.62 \%$, respectively, which gave the spherical biocarriers good physical strength [37]. The results suggest that spherical biocarriers are suitable for use as biocarriers of human hepatocytes.

3.3. Morphology of the Spherical Biocarriers from Gingko LCC. The spherical biocarriers prepared with gingko LCC were porous material as observed by optical microscopy and SEM. As shown in Figure 5(a), the spherical biocarrier is seen in light gray. The morphology of the spherical biocarriers demonstrated that the LCC particles were porous and suitable for cell biocarriers under culture conditions as shown in Figure 5(b).

3.4. Diameter Determination and the Stability. As a biomaterial, the large diameter of the biocarriers will decrease the specific surface area, whereas small diameters will increase the density of biocarriers. Both could impact the growth of cells. Therefore the diameter of biocarriers must be in the appropriate range for the particular cells. In this study, the dry and wet diameters of the spherical biocarriers are $1.8-2.0 \mathrm{~mm}$ and $1.9-2.1 \mathrm{~mm}$, respectively. There are some differences between dry and wet spherical biocarriers. The results indicated that the diameters of the spherical biocarriers were stable within a range that was suitable for cell culture. The stability of spherical biocarriers was determined when high concentrations of spherical biocarriers were suspended in a weak acid of $\mathrm{pH} 4-5$, a neutral solution of $\mathrm{pH} 7.4$, and an alkaline solution of $\mathrm{pH}$ 9.5. In Figure 6, it was found that the spherical biocarriers kept their intact diameter and style after 15 days in suspension. It was found that the spherical biocarriers had good stability and were suitable for cultivation at different $\mathrm{pH}$.

3.5. Specific Surface Area and Average Pore Size of the Spherical Biocarriers. Specific surface area and average pore size of spherical biocarriers were measured using a high precision surface tester. The BET curve is shown in Figure 7. The $V_{m}$ value can be calculated using the linear slope and intercept in Figure 7. According to (1) and Kelvin equation (2), the specific surface area and average pore size of spherical biocarriers were calculated to be $17.15 \mathrm{~m}^{2} \mathrm{~g}^{-1}$ and $21.59 \mathrm{~nm}$, respectively. The results revealed that the spherical biocarriers had a high specific surface area. Thus, the spherical biocarriers can provide enough surface for cell growth and increase the cell density. When the monolayer of cells undergoes a trypsin digestion process, the damage to cells can be reduced by the cells being easily removed from the medium, compared with conventional monolayer cell culture, because of the $3 \mathrm{D}$ culture structure with the use of spherical biocarriers.

3.6. Cell Growth and Metabolic Activities of Hepatocytes Adhered to Spherical Biocarriers. In the presence of the biocarriers, human hepatocytes (L-02) were cultured statically. As shown in Figure 8, it was found that the majority of hepatocytes adhered to the spherical biocarriers, indicating that the LCC is nontoxic, biocompatible, and suitable for the hepatocyte culture. Using cell counting, the cell growth conditions of experimental and control groups in suspension during days 1 to 5 were observed in Figure 9. The cultured cells of the experimental and control groups during the first 3 days grew slowly. On the 4 th day, the proliferation rate of the cells increased, which was greater in the experimental group compared to that of the control group.

In Figure 10, it was found that the content of albumin secretion (ALB) from the hepatocytes cultured on the porous biocarriers was significantly greater compared to the control group (without biocarriers). On the 4th day of cultivation the ALB value reached the highest level at $10.45 \mathrm{~g} \mathrm{~d}^{-1} \mathrm{~L}^{-1}$, while the control group had a high value of $6.89 \mathrm{~g} \mathrm{~d}^{-1} \mathrm{~L}^{-1}$. Therefore, The ALB value of the sample with the use of biocarriers was increased by $51.7 \%$ as compared with the control. As shown in Figure 11, the glucose consumption of the hepatocytes increased significantly with the use of 


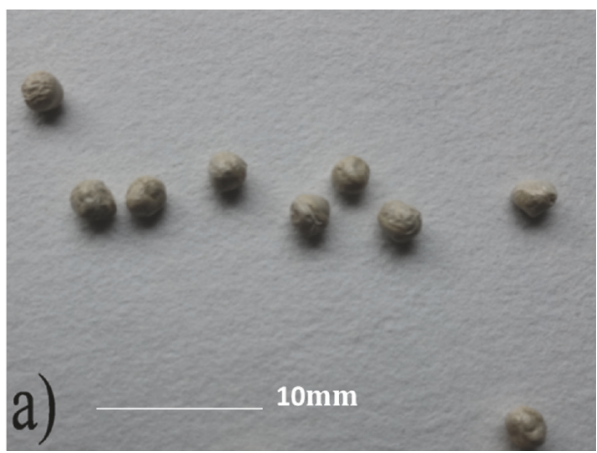

(a)

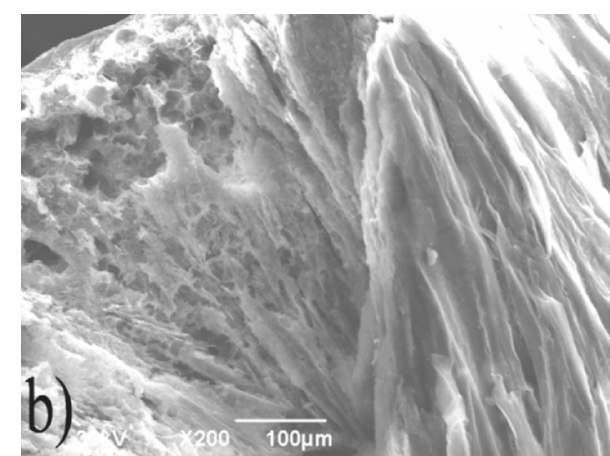

(b)

FIGURE 5: Morphological observations by stereomicroscopy (a) and SEM (b) of the spherical biocarriers prepared from gingko LCC.

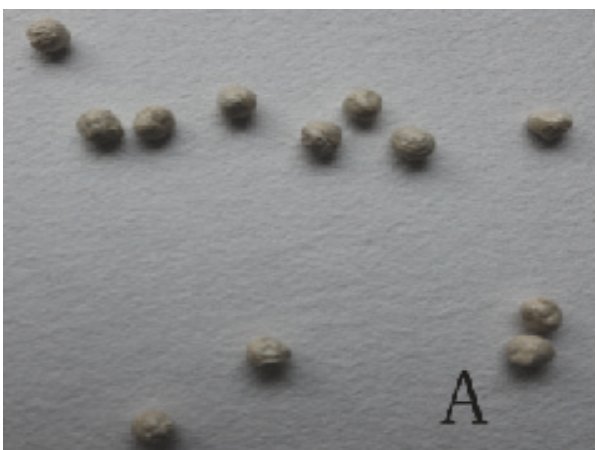

(a)

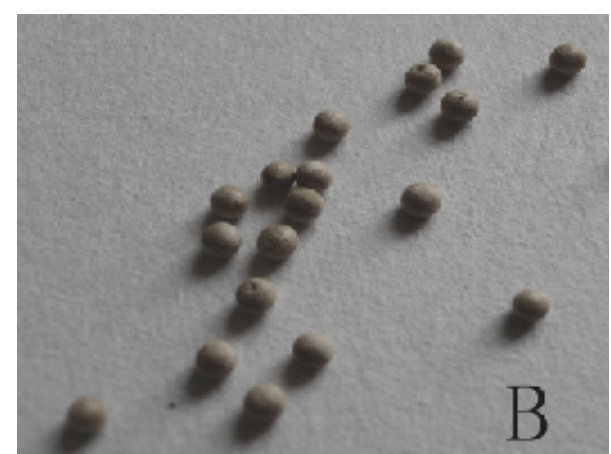

(b)

Figure 6: The morphology of spherical biocarriers before (a) and after 15 days (b) suspended in pH 7.4.

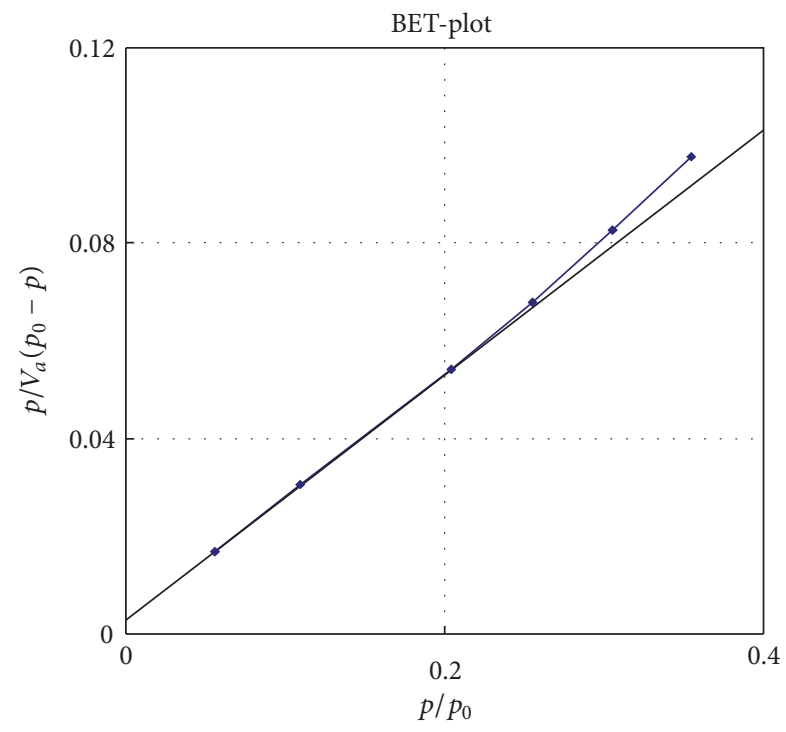

FIGURE 7: BET adsorption isotherm of the spherical biocarriers.

biocarriers when compared to the control experiment. In the 4th day of cultivation, glucose consumption reached the highest value of $14.0 \mathrm{mmol} \mathrm{d}^{-1} \mathrm{~L}^{-1}$, while the highest value was $10.1 \mathrm{mmol} \mathrm{d}^{-1} \mathrm{~L}^{-1}$ in the control group. This suggests that the glucose consumption value of sample using biocarriers is enhanced by $38.6 \%$ as compared with the control. These results indicated that the biocarriers using ginkgo LCC had biocompatibility with human hepatocytes. The LCC are a promising biomedical polymers that could be used in the tissue engineering of culture hepatocytes to create hepatic organs.

\section{Conclusions}

(1) The spherical carriers were prepared using lignincarbohydrate complexes from poplar wood with the liquid nitrogen freeze-drying method. It was found that the carriers were stable in aqueous solution. The specific surface area and average pore size were $17.154 \mathrm{~m}^{2} \mathrm{~g}^{-1}$ and $21.59 \mathrm{~nm}$, respectively. The specific surface analysis and SEM results indicated that the spherical carriers prepared from gingko LCC could provide a large cell growth platform.

(2) The FT-IR spectral analysis indicated that the spherical carriers were composed of lignin and polysaccharides. The spherical biocarriers had a typical LCC structure. The chemical analysis indicated that the contents of galactose, lignin, and total sugars were $3.30 \%, 23.90 \%$, and $64.62 \%$, respectively, giving good 


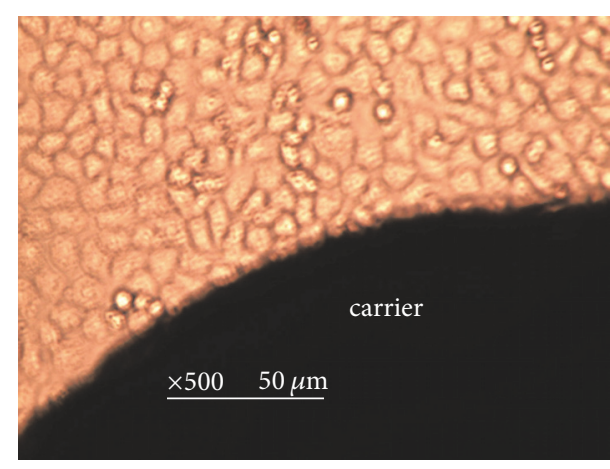

(a)

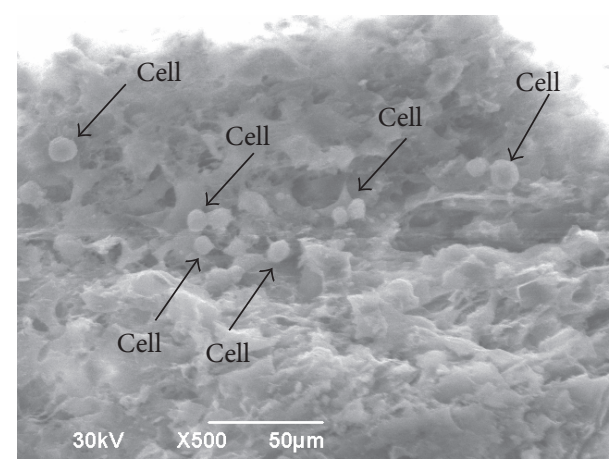

(b)

FIgURE 8: An inverted microscope image (a) and SEM image (b) of the human hepatocytes L-02 cultured on the spherical biocarriers.

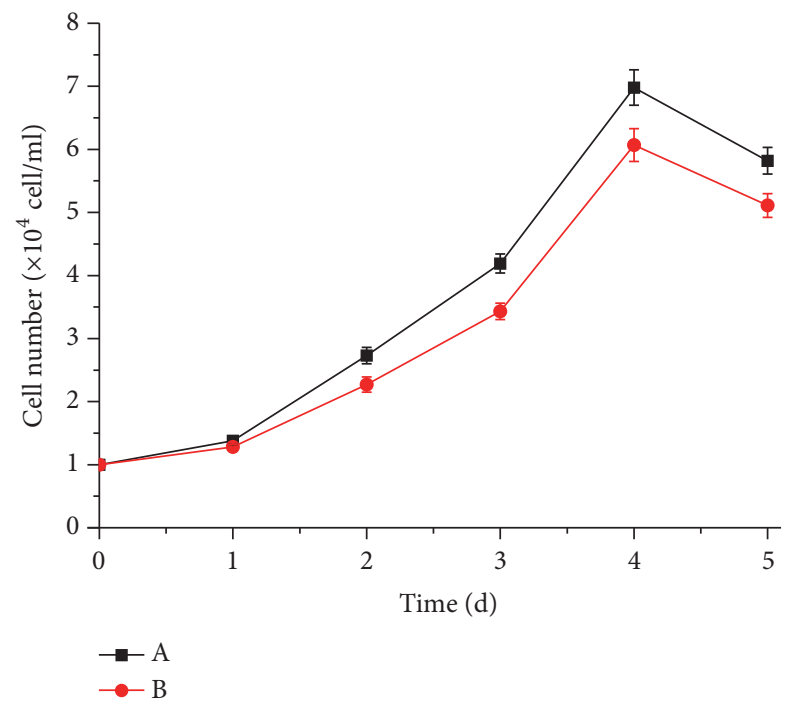

FIGURE 9: Cell counting of hepatocyte growth on spherical biocarriers (A) and control medium (B).

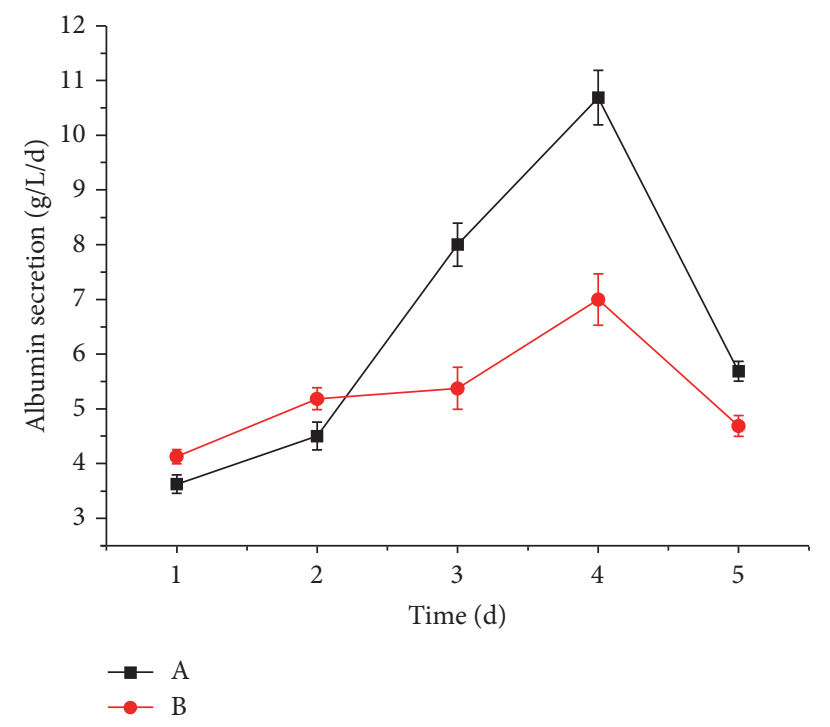

FIGURE 10: Albumin secretion by human hepatocytes cultured on biocarriers (A) and conventional media (B).

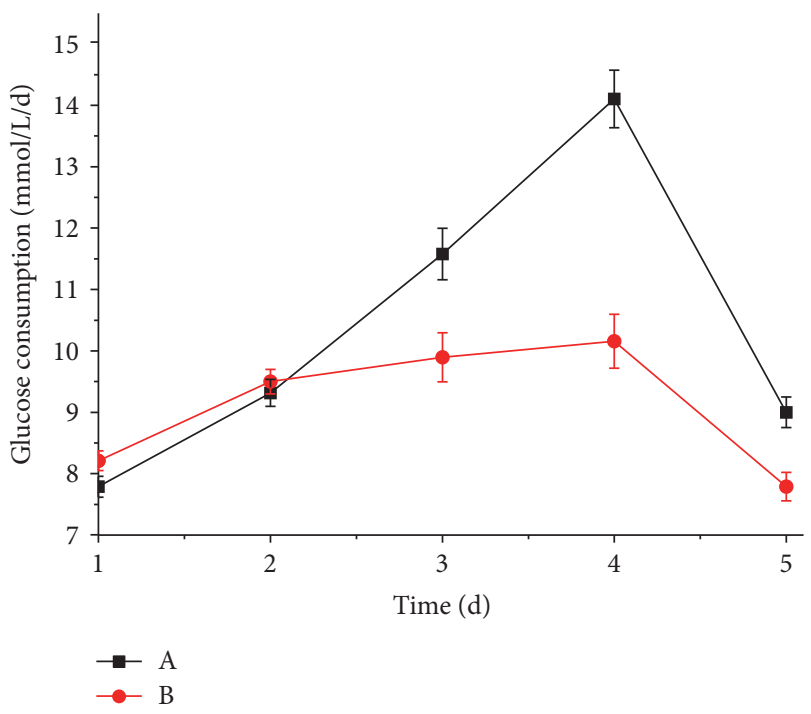

FIGURE 11: Glucose consumption of human hepatocytes cultured on biocarriers (A) and conventional media (B).

physical strength and compatibility of the biocarriers to hepatocytes.

(3) Cell counting showed that the cells increased faster than those of control group. It was also found that albumin secretion (ALB) value and glucose consumption of the human hepatocytes were enhanced by $51.7 \%$ and $38.6 \%$, respectively, when cultivated on the biocarriers. The results indicate that material of ginkgo LCC is very biocompatible and shows promise for use as a biomaterial in the culture of human hepatocytes.

\section{Conflicts of Interest}

The authors declare that they have no conflicts of interest in this work. 


\section{Acknowledgments}

The authors are grateful for the support of the National Natural Science Foundation of China (Grants no. 31370574 and no. 31300494) and Hubei Provincial Key Laboratory of Green Materials for Light Industry (Q20131402). The authors thank Professor Xue-Feng Li for his help in the preparation of the biocarriers.

\section{References}

[1] H. Sakagami, T. Kushida, and T. Oizumi, "Distribution of lignin-carbohydrate complex in plant kingdom and its functionality as alternative medicine," Pharmacology \& Therapeutics, vol. 128, no. 1, pp. 91-105, 2010.

[2] N. G. Lewis and E. Yamamoto, "Lignin: occurrence, biogenesis and biodegradation," Annual Review of Plant Biology, vol. 41, no. 1, pp. 455-496, 1990.

[3] J.-I. Azuma and K. Tetsuo, "Lignin-carbohydrate complexes from various sources," Methods in Enzymology, vol. 161, no. 1, pp. 12-18, 1988.

[4] R. Singh, S. Singh, K. D. Trimukhe et al., "Lignin-carbohydrate complexes from sugarcane bagasse: preparation, purification, and characterization," Carbohydrate Polymers, vol. 62, no. 1, pp. 57-66, 2005.

[5] T.-Q. Yuan, S.-N. Sun, F. Xu, and R.-C. Sun, "Characterization of lignin structures and lignin-carbohydrate complex (LCC) linkages by quantitative 13C and 2D HSQC NMR spectroscopy," Journal of Agricultural and Food Chemistry, vol. 59, no. 19, pp. 10604-10614, 2011.

[6] X. Du, M. Pérez-Boada, C. Fernández et al., "Analysis of lignin-carbohydrate and lignin-lignin linkages after hydrolase treatment of xylan-lignin, glucomannan-lignin and glucanlignin complexes from spruce wood," Planta, vol. 239, no. 5, pp. 1079-1090, 2014.

[7] M. H. Sipponen, C. Lapierre, V. Méchin, and S. Baumberger, "Isolation of structurally distinct lignin-carbohydrate fractions from maize stem by sequential alkaline extractions and endoglucanase treatment," Bioresource Technology, vol. 133, no. 4, pp. 522-528, 2013.

[8] Y. Xie, S. Yasuda, H. Wu, and H. Liu, "Analysis of the structure of lignin-carbohydrate complexes by the specific 13C tracer method," Journal of Wood Science, vol. 46, no. 2, pp. 130-136, 2000.

[9] A. Ghanem and M. L. Shuler, "Characterization of a perfusion reactor utilizing mammalian cells on microcarrier beads," Biotechnology Progress, vol. 16, no. 3, pp. 471-479, 2000.

[10] H. Sakagami, K. Hashimoto, F. Suzuki et al., "Molecular requirements of lignin-carbohydrate complexes for expression of unique biological activities," Phytochemistry, vol. 66, no. 17, pp. 2108-2120, 2005.

[11] H. Sakagami, M. Kawano, M. M. Thet et al., "Anti-HIV and immunomodulation activities of cacao mass lignin-carbohydrate complex," In Vivo, vol. 25, no. 2, pp. 229-236, 2011.

[12] H. Chung and N. R. Washburn, "Chemistry of lignin-based materials," Green Materials, vol. 1, no. 3, pp. 137-160, 2012.

[13] J.-B. Lee, C. Yamagishi, K. Hayashi, and T. Hayashi, "Antiviral and immunostimulating effects of lignin-carbohydrate-protein complexes from Pimpinella anisum," Bioscience, Biotechnology, and Biochemistry, vol. 75, no. 3, pp. 459-465, 2011.
[14] M. Zahedifar, F. B. Castro, and E. R. Ørskov, "Effect of hydrolytic lignin on formation of protein-lignin complexes and protein degradation by rumen microbes," Animal Feed Science and Technology, vol. 95, no. 1-2, pp. 83-92, 2002.

[15] C.-S. Cho, A. Kobayashi, R. Takei, T. Ishihara, A. Maruyama, and T. Akaike, "Receptor-mediated cell modulator delivery to hepatocyte using nanoparticles coated with carbohydratecarrying polymers," Biomaterials, vol. 22, no. 1, pp. 45-51, 2001.

[16] C. S. Seo, S. J. Park, I. K. Kim, S. H. Kim, and T. H. Hoshibac, "Galactose-carrying polymers as extracellular matrices for liver tissue engineering," Biomaterials, vol. 27, no. 4, pp. 576-585, 2006.

[17] J. Yang, C.-S. Cho, and T. Akaike, "Galactosylated alginate as a scaffold for hepatocytes entrapment," Biomaterials, vol. 23, no. 2, pp. 471-479, 2002.

[18] S. M. Roopan, "An overview of natural renewable bio-polymer lignin towards nano and biotechnological applications," International Journal of Biological Macromolecules, vol. 103, no. 1, pp. 508-514, 2017.

[19] T.-T. You, L.-M. Zhang, S.-K. Zhou, and F. Xu, "Structural elucidation of lignin-carbohydrate complex (LCC) preparations and lignin from Arundo donax Linn," Industrial Crops and Products, vol. 71, no. 4, pp. 65-74, 2015.

[20] I. Geffen and M. Spiess, "Asialoglycoprotein receptor," International Review of Cytology, vol. 137, no. 137b, pp. 181-219, 1993.

[21] S. Erakovic, D. Veljovic, P. N. Diouf, T. Stevanovic, and M. Mitric, "Electrophoretic deposition of biocomposite lignin/ hydroxyapatite coatings on titanium," International Journal of Chemical Reactor Engineering, vol. 7, no. 1, pp. 113-130, 2009.

[22] H. S. Mansur, A. A. P. Mansur, and S. M. C. M. Bicallho, "Ligninhydroxyapatite/tricalcium phosphate biocomposites: SEM/ EDX and FTIR characterization," Key Engineering Materials, vol. 284-286, pp. 745-748, 2005.

[23] M. Mastoby Martinez, B. Andrea Pacheco, and V. Marlene Vargas, "Histological evaluation of the biocompatibility and bioconduction of a hydroxyapatite-lignin compound inserted in rabbits' shinbones," Revista MVZ Cordoba, vol. 14, no. 1, pp. 1624-1632, 2009.

[24] T. W. Chung, J. Yang, T. Akaike et al., "Preparation of alginate/galactosylated chitosan scaffold for hepatocyte attachment," Biomaterials, vol. 23, no. 14, pp. 2827-2834, 2002.

[25] I.-K. Park, J. Yang, H.-J. Jeong et al., "Galactosylated chitosan as a synthetic extracellular matrix for hepatocytes attachment," Biomaterials, vol. 24, no. 13, pp. 2331-2337, 2003.

[26] N. Yang, L. Chen, M.-K. Yang et al., "In vitro study of the interactions of galactosylated thermo-responsive hydrogels with cells," Carbohydrate Polymers, vol. 88, no. 2, pp. 509-516, 2012.

[27] J.-Y. Wang, F. Xiao, Y.-P. Zhao, L. Chen, R. Zhang, and G. Guo, "Cell proliferation and thermally induced cell detachment of galactosylated thermo-responsive hydrogels," Carbohydrate Polymers, vol. 82, no. 3, pp. 578-584, 2010.

[28] M. H. Sipponen, C. Lapierre, V. Méchin, and S. Baumberger, "Isolation of structurally distinct lignin-carbohydrate fractions from maize stem by sequential alkaline extractions and endoglucanase treatment," Bioresource Technology, vol. 133, pp. 522-528, 2013.

[29] R. Chen, S. J. Curran, J. M. Curran, and J. A. Hunt, "The use of poly(l-lactide) and RGD modified microspheres as cell carriers in a flow intermittency bioreactor for tissue engineering cartilage," Biomaterials, vol. 27, no. 25, pp. 4453-4460, 2006. 
[30] A. Björkman, "Studies on Findy Divided Wood Part 3. Extraction of Lignin-carbohydrate Complexes with Neutral Solvent," Industrial and Engineering Chemistry Research, vol. 60, pp. 243251, 1957.

[31] C. Hansmann, M. Schwanninger, B. Stefke, B. Hinterstoisser, and W. Gindl, "UV-microscopic analysis of acetylated spruce and birch cell walls," Holzforschung, vol. 58, no. 5, pp. 483-488, 2004.

[32] J. Yan, Z. Fan, T. Wei, W. Qian, M. Zhang, and F. Wei, "Fast and reversible surface redox reaction of graphene- $\mathrm{MnO}_{2}$ composites as supercapacitor electrodes," Carbon, vol. 48, no. 13, pp. 3825-3833, 2010.

[33] E. Raymundo-Piñero, V. Khomenko, E. Frackowiak, and F. Béguin, "Performance of manganese oxide/CNTs composites as electrode materials for electrochemical capacitors," Journal of The Electrochemical Society, vol. 142, no. 1, pp. 325-333, 2007.

[34] J. Chirkova, I. Andersone, I. Irbe, B. Spince, and B. Andersons, "Lignins as agents for bio-protection of wood," Holzforschung, vol. 65, no. 4, pp. 497-502, 2011.

[35] N. Wellner, M. Kačuráková, A. Malovíková, R. H. Wilson, and P. S. Belton, "FT-IR study of pectate and pectinate gels formed by divalent cations," Carbohydrate Research, vol. 308, no. 1-2, pp. 123-131, 1998.

[36] S.-J. Seo, T. Akaike, Y.-J. Choi, M. Shirakawa, I.-K. Kang, and C.S. Cho, "Alginate microcapsules prepared with xyloglucan as a synthetic extracellular matrix for hepatocyte attachment," Biomaterials, vol. 26, no. 17, pp. 3607-3615, 2005.

[37] K. S. Vasanthan, A. Subramanian, U. M. Krishnan, and S. Sethuraman, "Role of biomaterials, therapeutic molecules and cells for hepatic tissue engineering," Biotechnology Advances, vol. 30, no. 3, pp. 742-752, 2012. 

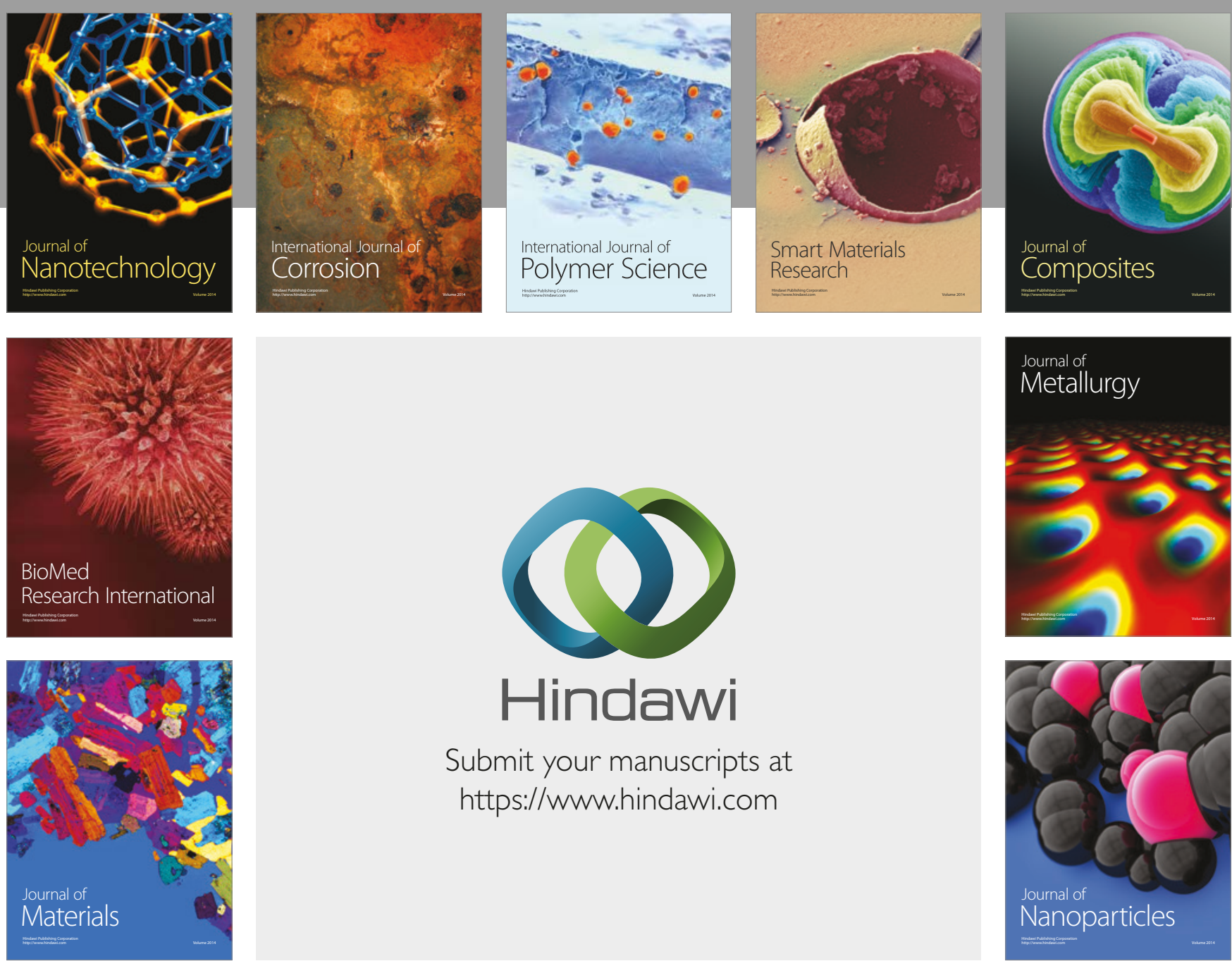

\section{Hindawi}

Submit your manuscripts at

https://www.hindawi.com
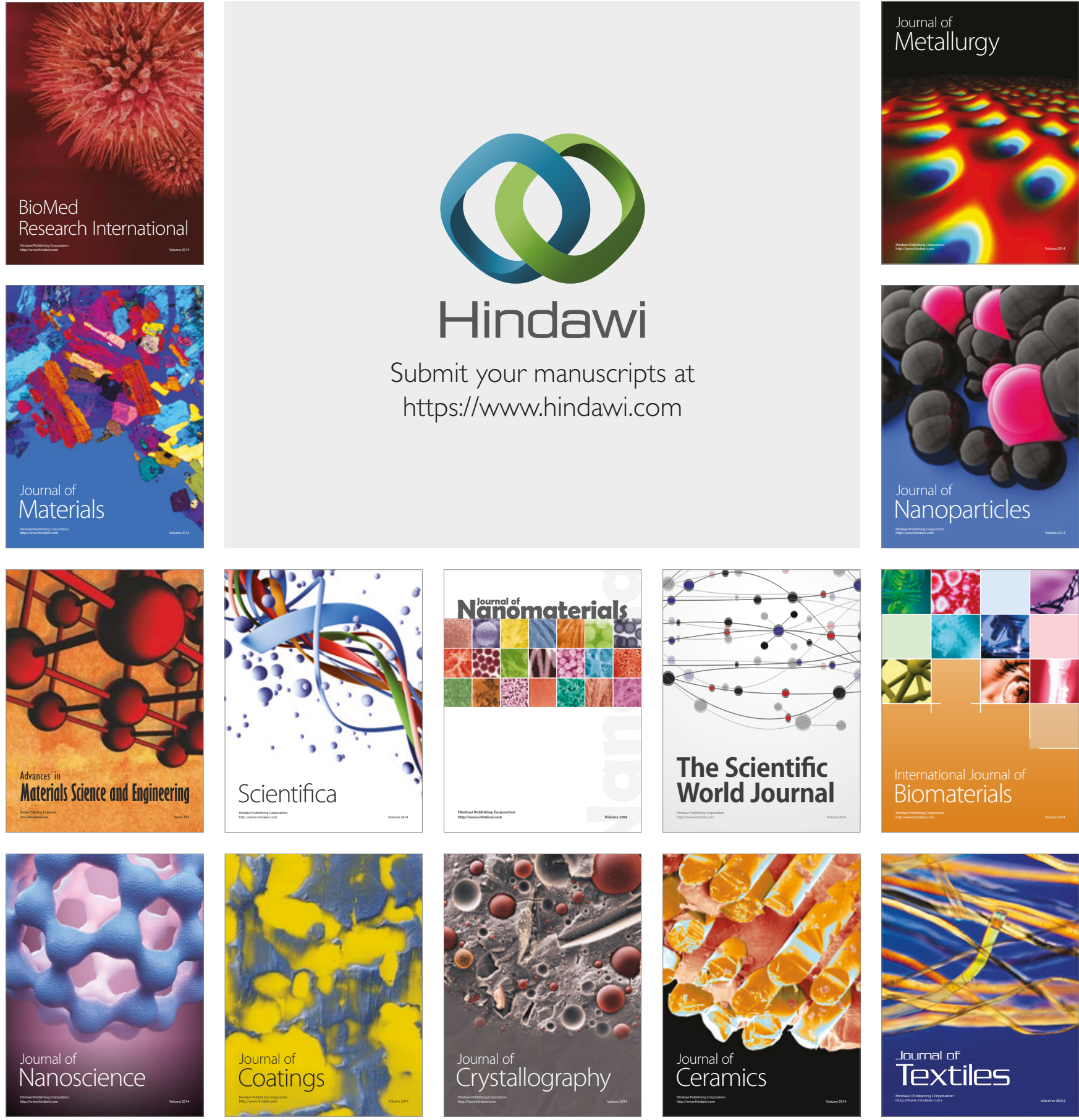

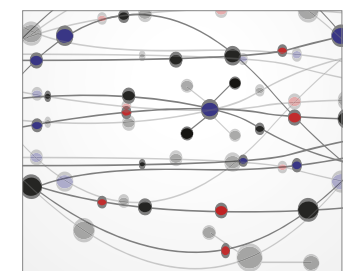

The Scientific World Journal
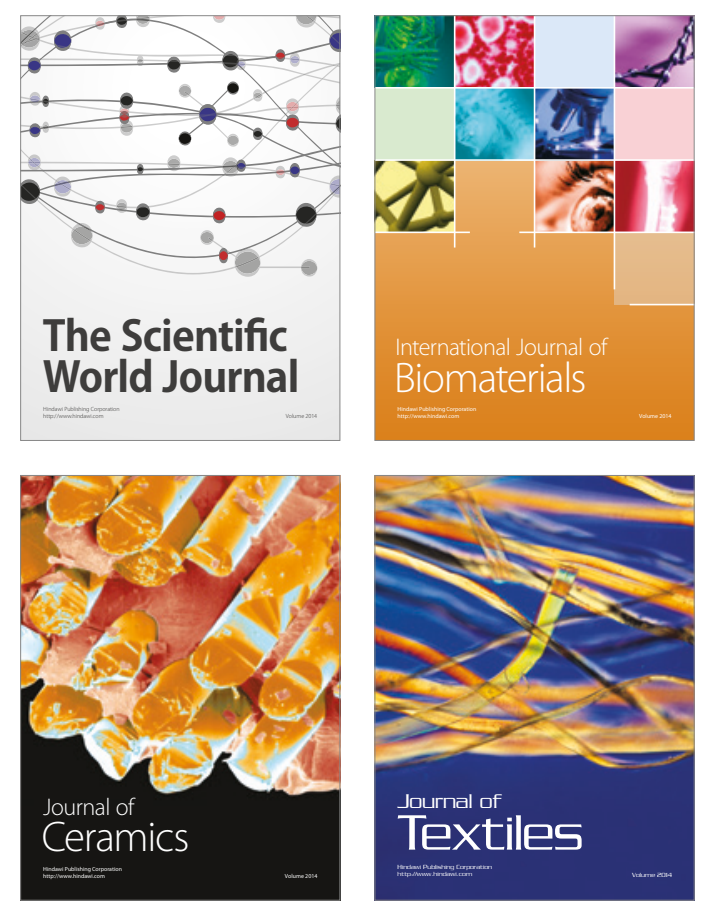